\title{
Relationship between Religion and Unintended Childbearing in Nigeria: A Cross-Regional Perspective
}

\author{
Kola' A. Oyediran ${ }^{1 *}$ (D) Gbenga Ishola ${ }^{2}$ and Akinrinola Bankole ${ }^{3}$
}

\author{
* Correspondence: kboyediran@ \\ gmail.com \\ 1John Snow Inc., Suite 4, 2733 \\ Crystal Drive, Arlington, VA 22202, \\ USA \\ Full list of author information is \\ available at the end of the article
}

\begin{abstract}
Context: Childbearing remains a global public health issue, posing an enormous challenge to families, communities, governments, program managers, and researchers, especially in developing countries.
\end{abstract}

Objective: The study examines the influence of religion on women's experience of unintended childbearing in Nigeria.

Method: Using the 2018 Demographic and Health Survey, the analysis focused on 13,109 women of reproductive age who had a birth within 2 years preceding the date of the interview. Multivariate logistic regression was used to examine the association between religion and unintended childbearing.

Results: Nearly 13\% of births in Nigeria over the last 2 years were unintended. The results showed that Muslims are less likely to experience unintended childbearing compared to Christians (Catholics as well as other Christians). In addition to religion having independent effects on unintended childbearing, the association between religion and unintended childbearing also depends on the region of residence. Muslims in the northern regions are less likely to have unintended births relative to Muslims in the southern regions.

Conclusion: Policy and program interventions to address unintended childbearing should take into consideration the country's religious diversity as well as regional sociocultural influences on reproductive preferences and behavior.

Keywords: Unintended childbearing, Women, Pregnancy, Reproductive health, Nigeria

\section{Background}

Unintended childbearing and its associated complications remain a major global concern to policymakers and program planners. Among the problems associated with carrying unintended pregnancies to term are delayed or lack of prenatal care-seeking behavior and fetal exposure to substance abuse which may lead to childhood mortality (Amo-Adjei \& Tuoyire, 2016; Bankole et al., 2015; Faye, Speizer, Fotso, et al., 2013; Sedgh, Bankole, Oye-Adeniran, et al., 2006). These problems are more prevalent in resource constraint settings including Nigeria (Ganatra, Gerdts, Rossier, et al., 2017).

(c) The Author(s). 2020 Open Access This article is licensed under a Creative Commons Attribution 4.0 International License, which permits use, sharing, adaptation, distribution and reproduction in any medium or format, as long as you give appropriate credit to the original author(s) and the source, provide a link to the Creative Commons licence, and indicate if changes were made. The images or other third party material in this article are included in the article's Creative Commons licence, unless indicated otherwise in a credit line to the material. If material is not included in the article's Creative Commons licence and your intended use is not permitted by statutory regulation or exceeds the permitted use, you will need to obtain permission directly from the copyright holder. To view a copy of this licence, visit http://creativecommons.org/licenses/by/4.0/. 
According to Bankole et al. (2015) in 2012, about one-third of all unintended pregnancies among women aged 15-49 resulted in unintended birth. In 2018, 11\% of all births in the past 5 years and current pregnancies were unintended (National Population Commission (NPC) [Nigeria] and ICF).

Nigeria has one of the highest fertility levels in sub-Saharan Africa, with a total fertility rate of 5.3, while the wanted fertility rate is 4.8 (National Population Commission (NPC) [Nigeria] and ICF), suggesting that Nigeria women are currently on the average having 0.5 more children than they want. The total fertility rate of 5.3 children per woman in 2018 is about $10 \%$ higher than the wanted fertility rate of 4.8 (National Population Commission (NPC) [Nigeria] and ICF). This means that about $9 \%$ of children that an average Nigerian woman has over her lifetime is unintended.

Previous studies have examined the prevalence and determinants of unintended birth in sub-Saharan Africa and globally using different approaches and methods (Adetunji, 1998; Roy \& Singh, 2016; Tebekaw, Aemro, \& Teller, 2014; Williams, 1991). These studies show positive relationships between unintended birth and women's sociodemographic and fertility-related variables, such as age, education, age at marriage, religion, number of living children, socioeconomic status, and exposure to family planning message through mass media. Unwanted childbearing in Bangladesh was significantly positively correlated with women's age and place of residence, but inversely correlated with education and social status (Roy \& Singh, 2016). An Ethiopia study showed that the burden of unintended childbearing was heavily shouldered by young, unmarried, less educated, wealthy, high parity, and ethnic majority women, and those from large households (Tebekaw et al., 2014). Among the factors he considered, Adetunji (1998) noted that the number of living children seems to be the most important predictor of recent unintended childbearing in developing countries.

Very few studies have examined the health impact of unintended childbearing in developing countries, especially in sub-Saharan Africa. According to a multi-country study in Bolivia, Egypt, Kenya, Peru, and the Philippines, mothers of children resulting from unwanted pregnancies were less likely to have received antenatal care compared to other women (Marston and Cleland, 2003). In India, children born from mistimed and unwanted pregnancies are more likely not to receive all recommended vaccinations and therefore died during neonatal and postnatal time (Ram, 2001), while in Malawi, $24 \%$ of children resulting from unwanted pregnancies were stunted (Baschieri et al., 2017).

This study examines the relationship between religion and unintended childbearing in Nigeria. It attempts to answer the following questions: How do religious differences influence unintended childbearing in Nigeria? Does this vary between the regions of residence? There are conflicting results from studies in sub-Saharan Africa and elsewhere on how religion as a covariate controlling for other variables influence unintended childbearing. Studies in India (Ram, 2001) and Ethiopia (Tebekaw et al., 2014) found that religion was associated with having unintended birth, whereas Roy and Singh (2016) found a lack of association between unintended childbearing and religion in Bangladesh. In the Ethiopian study, Tebekaw et al. (2014) and colleagues found higher odds of having an unwanted birth among Orthodox Christian women compared with Protestants, Muslims, and Catholics/traditional/others. 
The NDHS 2018 shows the important role of religion among Nigerians as almost 99\% identified with some form of organized religion (National Population Commission (NPC) [Nigeria] and ICF, 2019). The question that comes to mind therefore is how unintended childbearing differs between adherents of the two most prominent religionsChristianity and Islam. Even within the dominant religions, there may be variations in reasons for having an unintended birth along the line of denominations.

Examining the importance of religion as a predictor of unintended births can help develop better interventions to address the menace of unintended childbearing from religious perspectives since this has not been well researched considering the position and influence of religious leaders on the use of contraceptives. Demographers have renewed interest in the influence of religion on fertility behavior because of the perceived view that the influence of religion would remain constant after controlling other socioeconomic factors. And it is hypothesized that fertility within a given religious group could be explained by adherence to the tenets of the religion on childbearing (Agadjanian \& Prata, 2001; McQuillan, 2004) and that women who adhere strictly to the religion that opposes the use of contraceptives have higher risk to experience unintended births compared with others (Ikamari, 2000). Similarly, the likelihood of carrying an unintended pregnancy to birth is likely influenced by religion (Roy \& Singh, 2016).

\section{Theoretical framework}

The eco-social theory provides the frameworks for explaining women's childbearing intention for this study. The eco-social theory suggests that the overlap of individual and environmental factors, which intertwine with biomedical and behavioral risks, determines individual vulnerability and protection from adverse health conditions and outcome (Krieger, 2001; Krieger, 2005; Levins \& Lopez, 1999; McLaren \& Hawe, 2005; Singer et al., 2006; Singer \& Clair, 2003). This study builds on the previous studies that women's religious belief and the environment where they live influence their vulnerability to unintended childbearing. It is illustrative that the economic status cannot be enough to explain women's childbearing intention because every woman, irrespective of her wealth status, is at risk of unintended childbearing considering other factors including religious beliefs and social environment (Krieger, 2012). For example, a wealthy woman may be better able to prevent unintended childbearing than her poor counterpart, but still be at risk of having an unintended birth when her religious tenets prohibit contraceptive use, or when she lacks decision-making power. So, the age of onset of sexual activity, the regulation of non-marital sexual activity, contraception and abortion, and headship of the marital union are moral principles in religions but important in determining the risk of unintended childbearing. Another influencing factor is the region and the cultural milieu of religious practice, because religion and culture are intertwined. Thus, in the eco-social theory, it is implicit that religion, culture, and the social environment can be a driving force with regard to unintended childbearing.

\section{Data and methods}

Data

The data analyzed were drawn from the 2018 Nigeria Demographic and Health Survey (NDHS), using women's individual recode. NDHS is a nationally representative cross- 
sectional survey that uses a multistage stratified cluster probability sampling design, with clusters providing the primary sampling unit. The survey had a two-stage cluster sampling design consisting of 1400 enumeration areas (EA) that were selected with probability proportional to EA size. At the second stage, a fixed number of 30 households was selected in each cluster through equal probability systematic sampling, and a sample of women of reproductive age (15-49 years) in these households. The overall response rate for the NDHS 2018 was $99 \%$. Details of the survey and sampling procedure have been published elsewhere (National Population Commission (NPC) [Nigeria] and ICF). The analysis included 13,109 women of reproductive age who had a birth in the 2 years before the survey.

\section{Variables: operational definition}

The main outcome of interest is recent unintended childbearing, defined for this analysis using women's responses to the question about the planning status of their last child in the 2 years preceding the survey. Women who were currently not pregnant and who had at least one child were asked "whether they wanted their last child at the time of the conception." The responses were pre-coded as the following: wanted then, wanted later, or wanted no more. For this analysis, the variable, unintended birth, was coded as a two-category variable with a value of 1 if a woman had a child in the past 2 years and said she wanted a child later, or wanted no more children, and 0 otherwise.

The key independent variable is religion, which is defined as the respondent's religious affiliation (Catholic, other Christians, Muslim, and traditionalist/no religion). Christians other than Catholics are grouped together as "other Christians" because they are often collectively referred to as "Protestants" and their doctrines tend to be similar as compared to the Catholics. In addition, the NDHS does not collect data on "other Christians" by their denomination. Traditional religionists and people with no religions are grouped together because each group is very small. Furthermore, traditional religion involves worship of many gods and has diverse and less clearly articulated doctrines. Additional covariates of unintended childbearing identified in previous studies were included in the analysis (Ram, 2001; Tebekaw et al., 2014). The decision to include these covariates is based on the eco-social theory which posits that societal structures, which include religious affiliation, among others, often serve as a persuasion factor for women's perception about intendedness of births and secondly by the conclusions drawn by previous studies. Other covariates included were women's education, age, marital status, exposure to media, place of residence (urban vs. rural), the region of residence, sex of household head, household wealth index, number of living children, women's employment status, and women's participation in their own health decisionmaking.

Women's education was categorized into "no education," "primary education," "secondary," and "post-secondary education." The employment status was categorized as "working" and "not working." Exposure to family planning through mass media was included as a variable because previous studies have found it to have a significant negative association with unwanted childbearing (Roy \& Singh, 2016). A composite score of media exposure was created from women's responses to these questions on the use of mass media: if a woman read newspapers more than once a week, she scored " 1 " and 
" 0 " otherwise. A woman who had listened to the radio more than once a week was scored " 1 " and " 0 " otherwise. A woman who watched television more than once a week was scored " 1 " and " 0 " otherwise. Thereafter, the score for each woman was aggregated and ranged between 0 and 3, with a score of 0 meaning that the woman had no exposure to any mass media and a score of 3 meaning that she had access to all three. Scores were categorized into 0 "no media exposure," 1 "exposed to one source of media," 2 "exposed to two sources of media," and 3 "exposed to three sources of media."

Women's autonomy represented women's involvement in the household-level decision-making process using decisions about own health care as proxy. Women who said that they do make household-level decisions, either alone or jointly with their spouse in any of the four areas, were considered to have full autonomy, and women having no involvement in any decision-making were coded as having no autonomy (Oyediran \& Odusola, 2004; Feyisetan \& Oyediran, 2019). We included data on the sex of the head of the household as an important household characteristic with potential influence on unintended childbearing based on the societal norms, gender roles, and legal and policy environment. The head of household sex was coded as male or female.

Two geographic variables were used: place of residence (urban vs. rural) and region of residence. Nigeria consists of six geopolitical zones (or regions): north-central, north-east, north-west, south-east, south-south, and south-west. For the purpose of this paper, the six regions of residence were grouped into five: north-central, north-east, north-west, south-west, and south-east/south-south. The south-east and south-south regions were merged into one region due to the similarity in their religious composition (i.e., predominantly Christian with a small Muslim population). The population of two regions of the south-east and south-south are largely of either Catholic or Anglican faith; other Christian denominations constitute a smaller proportion.

Household wealth is an ordinal measure describing the poorest, poorer, middle, richer, and the richest households. Some fertility-related variables including women's age (15-24 years, 25-34 years, >=35 years) and type of marital union (never married, monogamous polygamous, and previously married) are included in the analysis. The number of living children was grouped into four categories: $0,1-2,3-4$, and 5 or more. It is expected that women in polygamous relationship and those who have more living children are more likely to have an unintended birth than their monogamous counterparts and those with fewer number of living children, respectively.

\section{Statistical analysis}

The analysis was performed using STATA 16.0 (StatCorp, 2019), and the survey analysis technique was applied because of the sample weight assigned by the Nigeria DHS and cluster design. The relationships between unintended childbearing and religious affiliation were explored using bivariate analysis and multivariate logistic regression. The chi-squared test was used to assess the association between religion, other covariates, and having an unintended birth. Odds ratios and 95\% confidence interval of odds ratios were estimated using multiple logistic regression models of the association between explanatory variables on the dependent variable (unintended birth). In addition, an interaction term was used to explore whether the association between religion and unintended childbearing differs according to region of residence. Altogether, four 
regression models were specified: the equation for the final model is specified below. Statistical significance was at $p<0.05$. The multivariate analysis results were reported in the form of odds rati, with odds ratios greater than 1 indicating higher odds of experiencing an unintended birth; odds ratios smaller than 1 indicate lower odds.

$$
\operatorname{Logit}(P(Y=1))=\beta_{0}+\beta_{1} X_{1}+\beta_{2} X_{2}+\beta_{3} X_{1} X_{2}+\beta_{4} X_{4}+\ldots+\beta_{\mathrm{i}} X_{\mathrm{i}}
$$

where

$P$ is the likelihood of having an unintended birth in the last 2 years

$Y$ is the experience of unintended birth in the last 2 years

$X_{1}$ is respondents' religion

$X_{2}$ is respondents' region of residence

$\beta_{1}$ and $\beta_{2}$ are the coefficients of religion and region of residence, respectively

$\beta_{3}$ is the coefficient of the interaction between religion and region of residence

$X_{4} \ldots . X_{i}$ are the other covariates in the model

$\beta_{4} \ldots \beta_{i}$ are the coefficients of the other covariates

If the interaction coefficient $\beta_{3}$ is significant, then the conclusion would be that the association between religion and the probability of unintended childbearing depends on the region of residence. The complex sample design of the 2018 Nigeria Demographic and Health Survey was accounted for in the computation of the standard errors of the estimates through the use of "svy" procedures in STATA 16. The adjusted Wald test was used to examine whether the additional parameters in models 2 to 4 contribute significantly to the fit of the first model.

\section{Results}

\section{Respondents' profile}

The analysis was restricted to 13,109 women of reproductive age who gave birth to a child in the last 2 years. Of these women, 12.8\% reported their last births in the last 2 years as unintended. Three-fifths belong to the Islamic faith and 30\% belong to Christian denominations other than Catholic, while $8.7 \%$ were Catholic. The remaining, less than $1 \%$, were adherents of traditional religion or those who reported no religious affiliation. The traditionalist or those who mentioned no religion were excluded from the multivariate analysis because of the small number of cases. Three in ten women of reproductive age included in the analysis were from the north-west and 10\% were from the south-west. Nearly half $(48.9 \%)$ of the women were $25-34$ years old with a mean age of 28.6 years. Forty-four percent had no formal education and $7.8 \%$ attained postsecondary education. More than one-third (35.2\%) had participated in their health decisions, which implies a low level of women's participation in their own health decisionmaking, particularly in a patriarchal society. Nearly $90 \%$ of the women were from household headed by male, and almost 70\% (67.5\%) belonged to the first three quintiles of the household wealth index, which means that a significant number of women were from the poor economic status group. About 68\% (67.8\%) were in monogamous union, $27 \%$ were in the polygamous union, and the remaining were either never married $(2.7 \%)$ or previously married or separated $(2.2 \%)$. About a quarter $(26.8 \%)$ had had five or more living children (Table 1). 


\section{Characteristics of women experiencing unintended childbearing}

About $13 \%$ of women's last births in the 2 years before the survey were unintended. The percentage of women whose last births in the past 2 years were unintended varied by women's characteristics (Table 2). The proportion with unintended births was highest among Christian women who were members of denominations other than Catholic (23.3\%), followed by women who reported traditional or no religion (20\%). The proportion was $17.5 \%$ among Catholic women and $6.7 \%$ among Muslim women. The proportion who had unintended births was higher among women residing in the south-east/ south-south region in comparison with those in north-central, north-east, north-west, and south-west.

Without controlling for the effects of other variables, women with secondary education $(20.9 \%)$ and primary education $(15.8 \%)$ tended to be more likely to report unintended births than those with no education (5.7\%) and those with post-secondary education (12.9\%). Table 2 also shows that residence and women's participation in their own health decision-making power were associated with greater incidence of unintended birth.

\section{Factors influencing unintended childbearing}

The multivariate analyses consist of four models fitted to examine the nexus among religion, other explanatory variables, and unintended childbearing Table 3). Model 1 includes women's religious affiliation as the sole explanatory variable. In model 2, geographical factors (region of residence, place of residence-urban vs. rural), individual attributes (women's education, women's age), and household wealth were added to model 1. In model 3, sociocultural factors (type of marital union, employment status, women's participation in their own health decision-making), mass media exposure to family planning message, and fertility behavior (number of living children) were added to model 2. Model 4 added the interaction term between religion and region of residence to model 3 . Ethnicity was not included in the multivariate analysis because it was found to be highly correlated with region of residence, which is one of the two main explanatory variables of interest. Women who were traditionalists or reported no religious affiliation were also excluded from the multivariate analysis because of the small number of cases. The results were presented in odds ratios, and $p$ values were presented to show the relative importance of the selected explanatory variables and their categories.

In model 1, the religious affiliation of women was statistically significantly related with having an unintended birth. Catholic and Muslim women $(\mathrm{OR}=0.65$ and $\mathrm{OR}=$ 0.24 , respectively) were less likely to have an unintended birth compared to women who belonged to Christian denominations other than Catholic. On controlling for women's geographical location and individual and household wealth index in model 2, women's religious affiliation remained a significant predictor of having an unintended birth. Also, region of residence was significantly associated with an experience of unintended childbearing. The odds of experiencing an unintended birth were significantly lower among women who resided in north-west $(\mathrm{OR}=0.61)$ compared with women living in the north-central region. On the other hand, women who were residing in south-east/south-south $(\mathrm{OR}=1.89)$ were more likely to experience an unintended birth compared to those who were living in the north-central. 
Table 1 Background characteristics of study participants (NDHS 2018), N=13,109

\begin{tabular}{|c|c|c|}
\hline Characteristics & Number & Percent \\
\hline \multicolumn{3}{|l|}{ Last birth intention } \\
\hline Intended & 11,432 & 87.2 \\
\hline Unintended & 1677 & 12.8 \\
\hline \multicolumn{3}{|l|}{ Religious affiliation } \\
\hline Catholic & 1146 & 8.7 \\
\hline Other Christians & 3986 & 30.4 \\
\hline Muslims & 7867 & 60.0 \\
\hline Traditionalist/no religion & 110 & 0.8 \\
\hline \multicolumn{3}{|l|}{ Region of residence } \\
\hline North-central & 2303 & 17.6 \\
\hline North-east & 2810 & 21.4 \\
\hline North-west & 3926 & 30.0 \\
\hline South-east/south-south & 2706 & 20.6 \\
\hline South-west & 1364 & 10.4 \\
\hline \multicolumn{3}{|l|}{ Women's age } \\
\hline $15-24$ years & 3980 & 30.3 \\
\hline 25-34 years & 6408 & 48.9 \\
\hline 35 years and above & 2721 & 20.8 \\
\hline \multicolumn{3}{|l|}{ Women's education } \\
\hline None & 5780 & 44.1 \\
\hline Primary & 1976 & 15.1 \\
\hline Secondary & 4334 & 33.0 \\
\hline Post-secondary & 1019 & 7.8 \\
\hline \multicolumn{3}{|l|}{ Place of residence } \\
\hline Rural & 8648 & 66.0 \\
\hline Urban & 4461 & 34.0 \\
\hline \multicolumn{3}{|l|}{ Employment status } \\
\hline Working & 8500 & 66.0 \\
\hline Not working & 4609 & 34.0 \\
\hline \multicolumn{3}{|l|}{ Type of employment status } \\
\hline Not working & 4609 & 35.2 \\
\hline Working and paid in cash only & 5951 & 45.4 \\
\hline Working and receiving cash and in-kind & 1127 & 8.6 \\
\hline Working and not paid & 1422 & 10.9 \\
\hline \multicolumn{3}{|c|}{ Women's participation in their own health decision-making } \\
\hline Participated in own health decision-making & 4815 & 36.7 \\
\hline Not involved in own health decision-making & 8294 & 63.3 \\
\hline \multicolumn{3}{|l|}{ Sex of head of household } \\
\hline Male & 11,896 & 90.8 \\
\hline Female & 1213 & 9.2 \\
\hline \multicolumn{3}{|l|}{ Household wealth quintile } \\
\hline First & 3030 & 23.1 \\
\hline Second & 3049 & 23.3 \\
\hline Third & 2763 & 21.1 \\
\hline
\end{tabular}


Table 1 Background characteristics of study participants (NDHS 2018), N=13,109 (Continued)

\begin{tabular}{lll}
\hline Characteristics & Number & Percent \\
\hline Fourth & 2404 & 18.3 \\
Fifth & 1863 & 14.2 \\
Mass media exposure to family planning message & & 68.3 \\
No exposure & 8957 & 19.6 \\
Exposed to one mass media source & 2567 & 9.4 \\
Exposed to two mass media sources & 1226 & 2.7 \\
Exposed to three mass media sources & 359 & 2.7 \\
Type of marital union & & 67.8 \\
Never married & 348 & 27.3 \\
Monogamous & 8888 & 2.2 \\
Polygamous & 3581 & \\
Previously married or separated & 292 & 1.4 \\
Number of living children & & 40.7 \\
None & 184 & 31.1 \\
1-2 children & 5341 & 26.8 \\
$3-4$ children & 4077 & \\
5 children and above & 3507 & \\
\hline
\end{tabular}

The odds of having an unintended birth were significantly lower among women aged $25-34$ years $(\mathrm{OR}=0.72)$ and significantly higher among older women (35 years and above) $(\mathrm{OR}=1.22)$ compared with women aged $15-24$ years. The odds of having an unintended birth were higher among women with primary education $(\mathrm{OR}=1.72)$, those with secondary education $(\mathrm{OR}=1.99)$, and those with post-secondary education $(\mathrm{OR}=1.22)$ in comparison with women with no education. In terms of household wealth index, women who belonged to the fifth quintile of household wealth index (OR $=0.73$ ) were significantly less likely to experience an unintended birth in comparison with those in the third quintile of household wealth index.

In model 3, after the inclusion of women's status variables (women's participation in their own health decision-making, type of marital union, and employment status), mass media exposure to family planning message, and fertility-related factors (number of living children), religious affiliation, region of residence, women's age, and women's education retained their significance. But the previously significant relationship between household wealth index and unintended childbearing was not retained. The effect of region of residence and women's age changed after the inclusion of variables related to women's status and fertility, indicating that women's status and fertility-related variables were also important predictors of unintended childbearing. Model 3 further confirms the results in the earlier two models about the relationship between religion and unintended childbearing after introducing women's status- and fertility-related variables. The results show that type of marital union, employment status, mass media exposure to family planning messages, and number of living children were significant predictors of women experiencing an unintended birth in Nigeria. For instance, women who were currently in polygamous union $(\mathrm{OR}=1.49)$ and those who were previously $(\mathrm{OR}=2.10)$ and never married $(\mathrm{OR}=11.08)$ were more likely to have had unintended birth compared with those who were currently in monogamous union. 
Table 2 Percent of women who experienced unintended in the past 2 years in Nigeria (NDHS 2018), $N=13,109$

\begin{tabular}{|c|c|c|}
\hline Characteristics & Percent & $p$ value \\
\hline \multicolumn{3}{|l|}{ Religious affiliation } \\
\hline Catholic & 17.5 & \multirow[t]{4}{*}{0.000} \\
\hline Other Christians & 23.3 & \\
\hline Muslims & 6.7 & \\
\hline Traditionalist/no religion & 20.0 & \\
\hline \multicolumn{3}{|l|}{ Region of residence } \\
\hline North-central & 11.5 & \multirow[t]{5}{*}{0.000} \\
\hline North-east & 8.0 & \\
\hline North-west & 5.3 & \\
\hline South-east/South-south & 27.4 & \\
\hline South-west & 17.7 & \\
\hline \multicolumn{3}{|l|}{ Women's age } \\
\hline $15-24$ years & 13.8 & \multirow[t]{3}{*}{0.000} \\
\hline $25-34$ years & 11.1 & \\
\hline 35 years and above & 15.2 & \\
\hline \multicolumn{3}{|l|}{ Women's education } \\
\hline None & 5.7 & \multirow[t]{4}{*}{0.000} \\
\hline Primary & 15.8 & \\
\hline Secondary & 20.9 & \\
\hline Post-secondary & 12.9 & \\
\hline \multicolumn{3}{|l|}{ Place of residence } \\
\hline Rural & 11.2 & \multirow[t]{2}{*}{0.000} \\
\hline Urban & 15.8 & \\
\hline \multicolumn{3}{|l|}{ Employment status } \\
\hline Working & 13.8 & \multirow[t]{2}{*}{0.000} \\
\hline Not working & 11.0 & \\
\hline \multicolumn{3}{|l|}{ Type of employment status } \\
\hline Not working & 11.0 & \multirow[t]{4}{*}{0.000} \\
\hline Working and paid in cash only & 13.8 & \\
\hline Working and receiving cash and in-kind & 11.5 & \\
\hline Working and not paid & 15.4 & \\
\hline \multicolumn{3}{|c|}{ Women's participation in their own health decision-making } \\
\hline Participated in her own health decision-making & 15.0 & \multirow[t]{2}{*}{0.000} \\
\hline Not involved in her own health decision-making & 11.5 & \\
\hline \multicolumn{3}{|l|}{ Household wealth quintile } \\
\hline First & 7.3 & \multirow[t]{5}{*}{0.000} \\
\hline Second & 9.6 & \\
\hline Third & 15.7 & \\
\hline Fourth & 18.8 & \\
\hline Fifth & 14.9 & \\
\hline \multicolumn{3}{|l|}{ Head of household sex } \\
\hline Male & 11.5 & \multirow[t]{2}{*}{0.000} \\
\hline Female & 25.9 & \\
\hline
\end{tabular}


Table 2 Percent of women who experienced unintended in the past 2 years in Nigeria (NDHS 2018), $N=13,109$ (Continued)

\begin{tabular}{lll}
\hline Characteristics & Percent & $p$ value \\
\hline Mass media exposure to family planning message & 11.8 & 0.000 \\
No exposure & 14.7 & \\
Exposed to one mass media source & 17.1 & \\
Exposed to two mass media sources & 9.8 & 0.000 \\
Exposed to three mass media sources & & \\
Type of marital union & 64.1 & \\
Never married & 11.9 \\
Monogamous & 9.2 & 0.000 \\
Polygamous & 22.3 \\
Previously married or separated & \\
Number of living children & 10.3 \\
None & 12.5 \\
1-2 children & 10.7 \\
$3-4$ children & 15.8 \\
5 children and above & & \\
\hline
\end{tabular}

The final model presents the two-way interaction terms between religious affiliation and region of residence in the full sample, controlling for women's sociodemographic, women's status, geographical, and fertility-related factors. With the interaction terms, the model reveals that women's religious affiliation and region of residence had independent effect on having unintended births among Nigerian women. In addition, the association between women's religion and unintended childbearing depended on the region of residence. For instance, the odds of experiencing an unintended birth was lower for women who were Catholic and living in the south-east/south-south $(\mathrm{OR}=0.52)$ as compared with Catholic women in the north-central. On the other hand, Muslim women who were residing in the north-east $(\mathrm{OR}=2.45)$ are more likely to an experience of unintended childbearing than their Muslim counterparts in the north-central. It is important to state that women's current age, education, type of marital union, employment status, mass media exposure to family planning message, and number of living children remained significantly associated with unintended childbearing with the inclusion of the interaction between religious affiliation and region of residence (Table 3).

Figure 1 presents the adjusted predicted probabilities of unwanted childbearing derived from the interaction terms between religious affiliation and region of residence after controlling the sociodemographic, women's position, and fertility-related factors. The figure suggests that the predicted probability of having an unintended childbearing tends to be lower among Muslim women in the northern regions of Nigeria compared to their Muslim counterparts in the southern regions. On the other hand, while there are large differences among Christians by region, the north-south dichotomy is not as clear-cut. For instance, while non-Catholic Christians tend to have lower probabilities of having unintended births in the north-west and north-east compared to their counterparts in the south-west and south-east/south-south, those in the north-central region have a similar probability of having unintended childbearing as those in the south-west. Among Catholic women, the probabilities of having an unintended birth are almost 
Table 3 Odds ratios of the association of unintended births with religion, region of residence, and other covariates among women in Nigeria (NDHS 2018)

\begin{tabular}{|c|c|c|c|c|}
\hline Explanatory factors & Model I (SE) & Model II (SE) & Model III (SE) & Model IV (SE) \\
\hline \multicolumn{5}{|l|}{ Religious affiliation } \\
\hline Catholic & $0.65(0.068)^{* * *}$ & $0.60(0.065)^{* * *}$ & $0.60(0.067)^{* * *}$ & $0.92(0.227)$ \\
\hline Other Christians & Ref & Ref & Ref & Ref \\
\hline Muslims & $0.24(0.021) * * *$ & $0.56(0.061)^{* * *}$ & $0.52(0.059)^{* * *}$ & $0.36(0.088)^{* * *}$ \\
\hline \multicolumn{5}{|l|}{ Region of residence } \\
\hline North-central & & Ref & Ref & Ref \\
\hline North-east & & $0.84(0.136)$ & $0.76(0.127)$ & $0.47(0.091)^{* * *}$ \\
\hline North-west & & $0.61(0.101)^{* * *}$ & $0.54(0.089)^{* * *}$ & $0.37(0.153)^{* * *}$ \\
\hline South-east/south-south & & $1.89(0.239)^{* * *}$ & $1.78(0.242)^{* * *}$ & $1.72(0.266)^{* * *}$ \\
\hline South-west & & $1.14(0.175)$ & $1.19(0.183)$ & $1.03(0.192)$ \\
\hline \multicolumn{5}{|l|}{ Women's age } \\
\hline $15-24$ years & & Ref & Ref & Ref \\
\hline $25-34$ years & & $0.72(0.059)^{* * *}$ & $0.51(0.048)^{* * *}$ & $0.52(0.048)^{* * *}$ \\
\hline 35 years and above & & $1.22(0.105)^{* *}$ & $0.57(0.066)^{* * *}$ & $0.57(0.067)^{* * *}$ \\
\hline \multicolumn{5}{|l|}{ Women's education } \\
\hline None & & Ref & Ref & Ref \\
\hline Primary & & $1.72(0.211)^{* * *}$ & $1.68(0.213)^{* * *}$ & $1.66(0.212)^{* * *}$ \\
\hline Secondary & & $1.99(0.234)^{* * *}$ & $2.29(0.272)^{* * * *}$ & $2.27(0.281)^{* * *}$ \\
\hline Post-secondary & & $1.29(0.224)^{* *}$ & $2.12(0.375)^{* * *}$ & $2.11(0.379)^{* * *}$ \\
\hline \multicolumn{5}{|l|}{ Place of residence } \\
\hline Urban & & $1.02(0.096)$ & $0.97(0.096)$ & $0.99(0.098)$ \\
\hline Rural & & Ref & Ref & Ref \\
\hline \multicolumn{5}{|l|}{ Household wealth quintile } \\
\hline First quintile & & $0.92(0.122)$ & $0.89(0.121)$ & $0.89(0.121)$ \\
\hline Second quintile & & $0.88(0.092)$ & $0.82(0.089)$ & $0.82(0.089)$ \\
\hline Third quintile & & Ref & Ref & Ref \\
\hline Fourth quintile & & $1.10(0.111)$ & $1.17(0.123)$ & $1.17(0.124)$ \\
\hline Fifth quintile & & $0.73(0.097)^{*}$ & $0.89(0.123)$ & $0.90(0.126)$ \\
\hline \multicolumn{5}{|l|}{ Type of marital union } \\
\hline Never married & & & $11.08(2.131)^{* *}$ & $11.74(2.346)^{* * *}$ \\
\hline Monogamous & & & Ref & Ref \\
\hline Polygamous & & & $1.49(0.127)^{* * *}$ & $1.49(0.127)^{* * *}$ \\
\hline Previously married or separated & & & $2.10(0.451)^{* * *}$ & $2.10(0.451)^{* * *}$ \\
\hline \multicolumn{5}{|l|}{ Employment status } \\
\hline Working & & & $0.84(0.068)^{*}$ & $0.83(0.068)^{*}$ \\
\hline Not working & & & Ref & Ref \\
\hline \multicolumn{5}{|c|}{ Women's participation in their own health decision-making } \\
\hline $\begin{array}{l}\text { Participated in her own } \\
\text { health decision-making }\end{array}$ & & & $0.99(0.079)$ & $0.99(0.080)$ \\
\hline $\begin{array}{l}\text { Not involved in her own } \\
\text { health decision-making }\end{array}$ & & & Ref & Ref \\
\hline \multicolumn{5}{|l|}{ Head of household sex } \\
\hline Male & & & $0.87(0.091)$ & $0.89(0.093)$ \\
\hline Female & & & Ref & Ref \\
\hline
\end{tabular}


Table 3 Odds ratios of the association of unintended births with religion, region of residence, and other covariates among women in Nigeria (NDHS 2018) (Continued)

\begin{tabular}{|c|c|c|c|c|}
\hline Explanatory factors & Model I (SE) & Model II (SE) & Model III (SE) & Model IV (SE) \\
\hline \multicolumn{5}{|c|}{ Mass media exposure to family planning message } \\
\hline No exposure & & & $0.81(0.070)^{*}$ & $0.81(0.069)^{*}$ \\
\hline $\begin{array}{l}\text { Exposed to one mass } \\
\text { media source }\end{array}$ & & & Ref & Ref \\
\hline $\begin{array}{l}\text { Exposed to two mass } \\
\text { media sources }\end{array}$ & & & $0.87(0.117)$ & $0.86(0.115)$ \\
\hline $\begin{array}{l}\text { Exposed to three mass } \\
\text { media sources }\end{array}$ & & & $0.40(0.097)^{* * *}$ & $0.40(0.098)^{* * *}$ \\
\hline \multicolumn{5}{|l|}{ Number of living children } \\
\hline None & & & $0.87(0.291)$ & $0.88(0.293)$ \\
\hline $1-2$ children & & & Ref & Ref \\
\hline 3-4 children & & & $1.79(0.162)^{* * *}$ & $1.79(0.162)^{* * *}$ \\
\hline 5 children and above & & & $4.10(0.472)^{* * *}$ & $4.14(0.473)^{* * *}$ \\
\hline \multicolumn{5}{|c|}{ Religious affiliation $\times$ region of residence } \\
\hline North-east $\times$ Catholic & & & & $0.73(0.409)$ \\
\hline North-east $\times$ Muslim & & & & $2.45(0.779)^{* * *}$ \\
\hline North-west $\times$ Catholic & & & & $1.95(1.315)$ \\
\hline North-west $\times$ Muslim & & & & $1.99(0.915)$ \\
\hline $\begin{array}{l}\text { South-east-South-south } \\
\times \text { Catholic }\end{array}$ & & & & $0.52(0.147)^{*}$ \\
\hline $\begin{array}{l}\text { South-east-South-south } \\
\times \text { Muslim }\end{array}$ & & & & $1.57(0.837)$ \\
\hline South-west $\times$ Catholic & & & & $0.55(0.346)$ \\
\hline South-west $\times$ Muslim & & & & $1.67(0.533)$ \\
\hline Constant & $0.31(0.017)^{* * *}$ & $0.15(0.025) * * *$ & $0.14(0.031)^{* * *}$ & $0.15(0.037)^{* * *}$ \\
\hline Adjusted Wald test (Prob $>F$ ) & & $22.50(0.000)$ & $20.73(0.000)$ & $0.11(0.738)$ \\
\hline Number of cases & 12,999 & 12,999 & 12,999 & 12,999 \\
\hline
\end{tabular}

${ }^{*} p<0.05,{ }^{* *} p<0.01,{ }^{* * *} p<0.001$

indistinguishable for those who were in the north-central and those in the south-east/ south-south. Similar probabilities of having unintended births are also observable for catholic women who were residing in the south-west and north-west.

\section{Discussion}

Our finding showed that $13 \%$ of women in Nigeria who delivered a child within the previous 2 years had experiences of unintended childbearing. We also found that women's religious affiliation is independently associated with unintended childbearing: Muslim women have a lower risk of unintended childbearing compared with their Christian counterparts. Doctrinally, both religions (Christianity and Islam) and their denominations (mainly Catholic vs. Protestant and Sunni vs. Shi'ite, respectively) teach their adherents that nothing happens to them unless God allows it. With respect to childbearing, both Christianity and Islam teach that life begins from the womb, and every pregnancy is an act of God that must be embraced as a gift. Based on these teachings, adherents of either religion may not consider a pregnancy as unintended, even if it was unintentionally conceived, especially when the pregnancy was carried to term. 


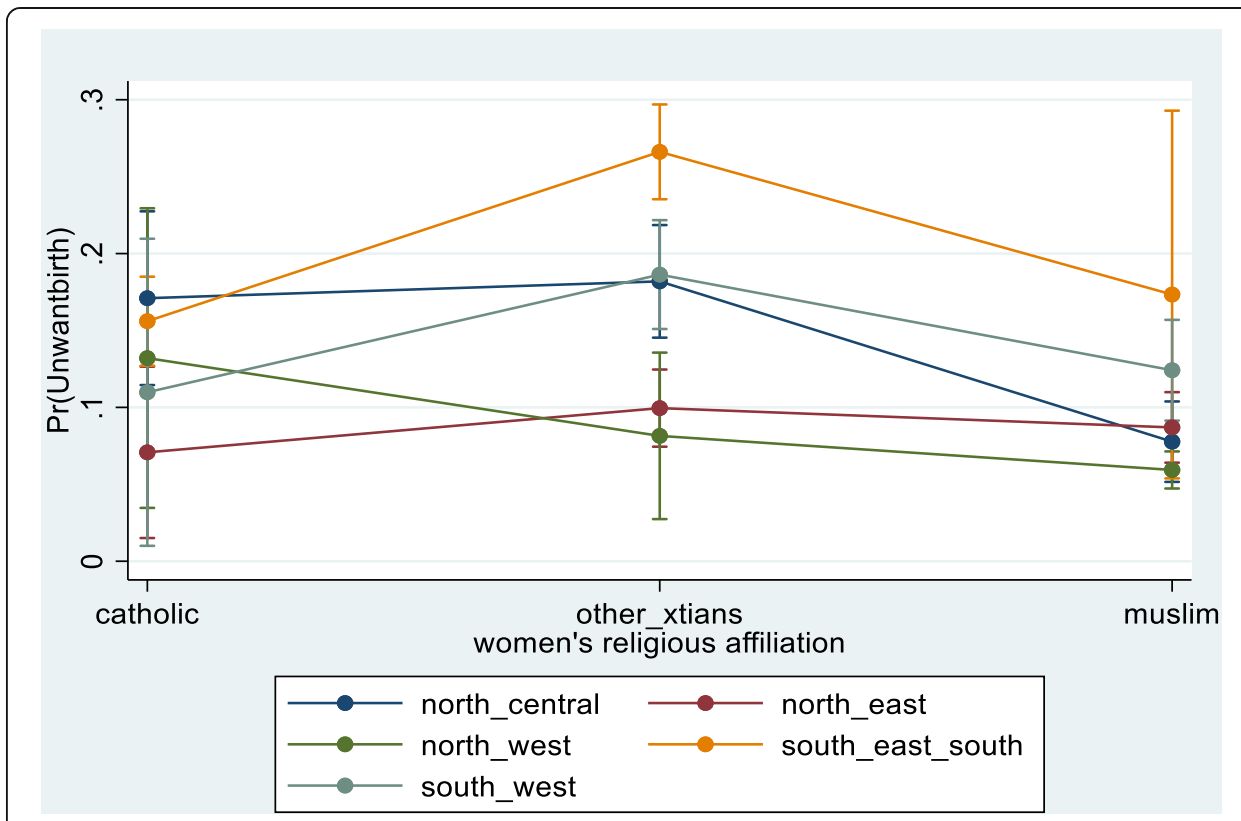

Fig. 1 Probability of women experiencing unintended pregnancy among women according to religion and region in Nigeria (NDHS, 2018)

Secondly, adherents of both faiths are taught to believe that God has a purpose and a plan for every child's life from conception. The child's value from God's perspective and a believer's positive and emotional expectation surrounding the new birth are likely to outweigh any unpleasant circumstance that may be associated with the pregnancy being unplanned.

It should be noted, however, that this does not imply that the religious teachings or practice encourage irrational childbearing. Christians and Muslim leaders often teach their followers to promote individual and family welfare from the viewpoint of health and economic well-being, including the timing of their births. Thus, both religions and their denominations generally permit the use of birth control methods, despite some variations in the type of birth control methods permitted or advocated. As Stacey puts it, "Family planning is embraced by religions across the spectrum as a moral good, a responsible choice, and a basic human right," because religions see family planning as a means for building strong family, protecting maternal and child health, reducing abuse, and preventing unintended childbearing (Blake \& Katrak, 2002; Stacey, 2019; World Bank, 2018). Even the Catholic teaching, which tends to be the most conservative, sees effective family planning as "reliable knowledge of the cycle of female fertility and a willingness to agree to abstain from sexual union at certain times" (p.57) (Catholic Bishops' Conference of England and Wales, 2004). But if a pregnancy occurs when it is not expected, adherents are admonished to accept it as an act of God.

The significant difference by religion in the observed risks of unintended childbearing, despite the fact that the Muslim and Christian religions have similar tenets regarding childbearing, suggests that Christian women may be less conservative in their interpretation and application of the teachings than their Muslim counterparts. This may be associated with a number of reasons, including differential desires for children and value of children. For instance, in Nigeria, Muslim women desire and have more 
children compared to Christian women (Adebowale et al., 2019; Oyediran, 2006; Westoff \& Bietsch, 2015). This may in part be driving the finding that the former have a higher risk of experiencing unintended births than the latter. Another potential explanation for the differential experience of unintended childbearing by religion despite similar tenets regarding childbearing is ex-post rationalization of fertility preferences. Several studies have noted that women, especially in developing countries, tend to rationalize an unintended pregnancy as intended following delivery and the likelihood of this behavior tends to increase with the age of the child (Bankole \& Westoff, 1998; Yeatman \& Sennott, 2015; Hall, Stephenson, \& Barrett, 2019). Some of these studies (e.g., Bankole \& Westoff, 1998; Hall et al., 2019) also found that ex-post rationalization varies by women's characteristics, with higher parity women been more likely to revise their pregnancy intentions over time, following delivery. Given that Muslim women tend to have a higher parity than Christian women in Nigeria, the former may be more likely to rationalize an unintended pregnancy as intended births compared to the latter.

The findings also revealed that the relationship between religion and unintended childbearing depends on the region of residence. Thus, as evident from the final model and Fig. 1, the predicted probability of having unintended childbearing indicated that Muslim women who lived in the northern regions of Nigeria had lower experiences of unintended childbearing compared to their Muslim counterparts in the southern regions. However, while Christians' unintended childbearing experiences differ by the region they lived in (e.g., north-east vs. south-west), no clear difference is observed by the classical north-south dichotomy. For example, Catholic women living in the south-east/ south-south tended to have similar experiences of unintended births as their counterparts in the north-central region. This implies that with respect to experiences of unintended pregnancy, Christians tended to be more responsive to regional heterogeneity than their Muslim counterparts. In other words, over and above religion, Christian women's experiences of unintended childbearing were more affected by variations in the sociocultural dynamics of the six regions in the country compared to those of Muslim women. For instance, in the north, the social, ethnic, and economic diversities of the north-central region associated with its inclusion of the Federal Capital tended to produce different experiences of unintended childbearing among Christians, especially Catholics, in the north than among Muslims in the north. These findings are consistent with the eco-social theory (Krieger, 2001; Krieger, 2005; Singer et al., 2006) and the study question about whether unintended childbearing varies by the regions of residence. The implication of this finding is that the environment and sociocultural dynamics of the region where women live influence experiences of unintended childbearing. The key driver of this pattern may be the fact that the north-central region has become the melting points of the north-south cultural norms and values. As a result, the western and liberal values tended to have diffused among Christians in the region, thereby making them to behave more like Christians in the south rather than their Christian or Muslim counterparts in the north. This indicates that the current study linked women's experience of having unintended childbearing to the norms and values of where they lived.

The above explanation is consistent with the eco-social theory that provided the framework for this study. This may explain why the non-Catholic Christian women in the north-central have a similar pattern of unintended childbearing as their non- 
Catholic Christian counterparts in the south-east-south-south and south-west. The north-central has become a confluence of norms, greater social interactions, and values as well as greater exposure to western influence which could have contributed to the probable liberal attitude of women residing in the north-central. Furthermore, the human capital development index, which could be associated with the level of investment in child education, is more robust in the southern and north-central regions compared to the north-east and north-west (World Bank, 2018). Though an average family in the southern and north-central regions wants every one of its children to be educated, child education is relatively less of a priority for an average family in the north-east and north-west. Given that child education has become even more expensive today, due to dwindling resources, women in the southern and north-central may be more likely to acknowledge that a birth is unintended than their north-east and north-west counterparts and are more prepared to bear the brunt of unintended births.

The finding that Catholic women in the south-west region are less likely to report unintended childbearing than their Catholic counterparts in the north-central is a little surprising. However, there is a greater variation among sociocultural norms and practices in the north-central region than in the South west region, both because of the characteristics of the states grouped into that region and because the region also includes the federal capital, with its influx of people from other parts of the country. Secondly, the Catholic conservative views of sexual relations in the southern regions, especially south-east and south-west regions or the diffusion of sociocultural norms and values in some parts of the north-central region suggest more liberal views of sexual relations could be adduced to the observed result among Catholic women. For instance, in Nigeria, the Tiv speaking people in the north-central region have the culture of using their wives to entertain guests sexually (Kadiri, Ahmad, \& Mustaffa, 2014). In such a culture, unintended pregnancy is likely to be common and less stigmatized.

Similar to religion, region of residence maintained independent association with unintended childbearing, over and above the association induced by religion. This is not surprising, given that region of residence may be associated with many factors some of which are not measured or easily observable, such as ethnicity or social stigma. The sociocultural context of the region where women reside is likely to exert strong influence on women's experiences of unintended childbearing. This is consistent with the assumption and postulation guidance of the eco-social theory that the context of the environment in terms of social, economic, geographical, and political along personal attributes influences individual behavior.

This study also reveals that other sociodemographic variables (women's age, women's education, type of marital union, employment status, mass media exposure to family planning message, and number of living children) are important determinants of unintended childbearing in Nigeria. The prevalence of unintended childbearing decreased with increasing women's age in Nigeria, so that the youngest women (aged 15-24) are more likely to report having had unintended childbearing than their older counterparts. The finding is contrary to findings from some studies that show that the likelihood of experiencing unintended births is higher among older women (Geda \& Lako, 2011; Noor, Rahman, Rob, \& Bellows, 2012). This is likely a result of generational differences and where women are in their reproductive lifespan. Younger women (especially unmarried women) tend to desire fewer children than older ones, and they are more likely 
to want to delay or postpone childbearing and to admit that a child is unintended. Modernization, high level of exposure, and social contacts with outside culture might also account for while younger women compared with older ones will most likely report unwanted births.

Our finding that unintended childbearing is significantly associated with education is consistent with studies in Ethiopia (Tebekaw et al., 2014) and Bangladesh (Roy \& Singh, 2016). However, the difference occurred only among highly educated women (i.e., with a post-secondary education), who were about half as likely to experience unintended births as women below this educational level. This confirms the role of education in preventing unintended childbearing. The prevalence of unintended childbearing increases with increasing number of living children. Women who have five or more living children are about four times as likely to experience unintended births compared to those with one to two living children. This suggests that as women have more living children and become satisfied with their fertility achievement, they desire to stop childbearing or postpone another birth. They are therefore more likely to report unintended births compared to women with fewer number of living children.

As Nigerian women and couples increasingly desire to have smaller families and to do so by spacing or limiting their births, investments in health care programs and policies must address the growing demand for family planning services. For instance, 19\% of women in Nigeria have an unmet need for family planning (National Population Commission (NPC) [Nigeria] and ICF). Meanwhile, if all individuals and couples who wished to avoid pregnancy used a method of contraception, some unintended pregnancies would still occur, and significant numbers of those pregnancies would end in births due to environmental factors such as religious faiths. Thus, it is necessary to help couples and families manage unintended childbearing to optimize health and well-being, including access to quality maternal and child health and socioeconomic development. Such investments are imperative to achieving universal access reproductive health rights and gender equity, as endorsed in the UN Sustainable Development goals.

Our findings point out the need for interventions to address unintended childbearing as a pervasive sexual and reproductive health concern in Nigeria. Policy initiatives could support development of strategies and programs to reduce unintended births. Our study shows that religious and cultural factors are important in designing evidence-informed interventions on sexual and reproductive health, especially when targeting approaches to avoid unintended childbearing. The interventions should take into account the influence of religious, social, and cultural views and their regional variations. It is crucial to recognize that a woman's values and her decisions on sexual and reproductive health may not align as strongly with those of her religion as with the social and environmental norms of her place of residence.

\section{Limitations}

Our study is not without some important limitations. The measure of unintended childbearing is based on retrospective information with its inherent biases. Typically, women tend to under-report unintended pregnancy or birth, and the extent of underreporting is associated with time elapsed since the conception. The further away the interview date from the time of conception, the more likely that women would report a pregnancy or birth was not intended before the pregnancy occurs as intended (Bankole 
\& Westoff, 1998). But this is not necessarily irrational or inaccurate information. Apart from the fact that fertility intention is not necessarily static, we lack qualitative data on how women feel about having unintended births in a society that welcomes newborn with dancing and pageantries. Nevertheless, we do not expect gross under-reporting in this study, because we focused on the births occurring up to 2 years before the survey.

Another limitation is that our data do not include a measure of the intensity of women's religious adherence. We expect that women's experience of unintended pregnancy may be affected by the extent to which they embrace their faith and its teachings, as may be indicated by how much they attend religious services and other programs. This measure often emerges as a stronger predictor of reproductive knowledge and behavior than whether or not a woman belongs to any religious group. Unfortunately, the Demographic and Health Survey does not include information that enables us to construct an indicator of religious adherence. Having this information and assessing its interaction with region would have shed more light into the subject of this paper.

Finally, the relationships we explore between having unintended birth and religion, region of residence, and the other covariates are at best considered associations rather than effects or impact. This is largely because of the cross-sectional nature of the data which makes it impossible for us to ascertain the temporal order of the variables, particularly the outcome variable vis-à-vis the predictor variables. Also, though we measured an unintended birth as an event that occurred within the last 2 years, we measured explanatory factors as of the date of the interview, and as current measures. Some of these values (level of education or number of living children) may have remained constant over more than 2 years, but this cannot be said for some others, such as age. Since we cannot clearly determine the timing of the outcome variable against that of most of the independent variables, the relationships described in this study between unintended pregnancy and the independent variables do not imply causality.

\section{Conclusions}

Our findings showed that religion is associated with experience of unintended births. This is consistent with the eco-social theory that posits that religion tenets influence women's and communities' attitudes, perceptions, and behaviors, including those on reproductive health, and thus, religion has a bearing on programs and policies for addressing the problem of unintended childbearing in Nigeria. Thus, though policy programs to improve maternal health should routinely include both religious leaders and men, they should also take into account the significant influence of region-specific factors and cultural characteristics, to ensure that women and couples can meet their fertility goals and reduce excess fertility.

\section{Acknowledgements}

The authors would like to thank ICF International implementer of the MEASURE DHS program for granting access to the 2018 Nigeria Demographic and Health Survey (NDHS). The authors would like to thank Stephanie Joyce who reviewed and edited the manuscript which helped make the paper more concise and is highly appreciated. More importantly, the authors acknowledge the paper reviewers, who provided new insights to improve this work for publication. The views and opinions expressed in this paper are solely those of the author and do not represent the view of his institution. 
conceived the theoretical framework used for the study. $\mathrm{KAO}, \mathrm{Gl}$, and $\mathrm{AB}$ equally contributed to the revision of important intellectual content in the manuscript. All authors have read and approved the final manuscript.

\section{Funding}

This research received no specific grant from any funding agency, commercial entity, or not-for-profit organization.

Availability of data and materials

Dataset is available from https://dhsprogram.com/data/dataset/Nigeria_Standard-DHS_2013.cfm?flag=1.

\section{Competing interests}

The authors have no conflicts of interest to declare.

\section{Author details}

${ }^{1}$ John Snow Inc., Suite 4, 2733 Crystal Drive, Arlington, VA 22202, USA. ${ }^{2}$ Cambridge Education Nigeria Limited, Abuja, Nigeria. ${ }^{3}$ Guttmacher Institute, New York, NY, USA.

Received: 18 February 2020 Accepted: 15 June 2020

Published online: 08 July 2020

\section{References}

Adebowale, A. S., Asa, S., Abe, J. O., \& Oyinlola, F. F. (2019). Sex preference, religion and ethnicity roles in fertility among women of childbearing age in Nigeria: Examining the links using zero-inflated Poisson regression model. International Journal of Statistics and Probability, 8(6), 91-106.

Adetunji, Jacob A 1998 Unintended childbearing in developing countries: Levels, trends, and determinants. DHS Analytical Reports No. 8. Calverton, Maryland: Macro International Inc.

Agadjanian, V., \& Prata, N. (2001). War and reproduction: Angola's fertility in comparative perspective. Journal of Southern African Studies, 27(2), 329-347.

Amo-Adjei, J., \& Tuoyire, D. A. (2016). Effects of planned, mistimed and unwanted pregnancies on the use of prenatal health services in sub-Saharan Africa: A multicounty analysis of Demographic and Health Survey data. Tropical Medicine and International Health Dec, 21(12), 1552-1561.

Bankole, A., \& Westoff, C. F. (1998). The consistency and validity of reproductive attitudes: Evidence from Morocco. Journal of Biosocial Science, 30(4), 439-455.

Bankole, A., Adewole, I., Hussain, R., Awolude, O., Singh, S., \& Akinyemi, J. (2015). The incidence of abortion in Nigeria. International Perspectives on Sexual and Reproductive Health, 41(4), 170-181.

Baschieri A, Machiyama K, Floyd S, Dube A, Molesworth A, Chihana M, et al. 2017. Unintended childbearing and child growth in northern Malawi. Maternal and Child Health Journal21(3):467-474. pmid:27491527

Blake, S. and Katrak, Z. 2002. Faith, values and sex and relationships education, National Children's Bureau.

Catholic Bishops' Conference of England and Wales. 2004. Cherishing life. The Catholic Truth Society and Colloquium (CaTEW) Ltd. London, 2004. http://www.bioethics.org.uk/images/user/cherishing-life-2004.pdf

Faye, C. M., Speizer, I. S., Fotso, J. C., et al. (2013). Unintended pregnancy: Magnitude and correlates in six urban sites in Senegal. Reproductive Health, 10, 2-10.

Feyisetan, B., \& Oyediran, K. A., (2019). Can married or cohabiting women negotiate protective sex? Findings from Demographic and Health Surveys of two West African countries. Journal of Biosocial Science. https://doi.org/10.1017/ S0021932019000798

Ganatra, B., Gerdts, C., Rossier, C., et al. (2017). Global, regional, and sub regional classification of abortions by safety, 2010-14: Estimates from a Bayesian hierarchical model. The Lancet, 390, 2372-2381.

Geda, N. R., \& Lako, T. K. (2011). A population based study on unintended pregnancy among married women in a district in southern Ethiopia. Geography and Regional Planning, 4(7), 417-427.

Hall, J. A., Stephenson, J., \& Barrett, G. (2019). On the stability of reported pregnancy intentions from pregnancy to 1 year postnatally: Impact of choice of measure, timing of assessment, women's characteristics and outcome of pregnancy. Maternal and Child Health Journal, 23, 1177-1186 https://doi.org/10.1007/s10995-019-02748x.

Ikamari, L. (2000). The magnitude and correlates of unintended childbearing in Kenya: Implications for the family planning programme. African Journal of Health Sciences, 7, 3 3-4 6.

Kadiri, K. K., Ahmad, M. K., \& Mustaffa, C. S. (2014). HIV/AIDS and cultural practices in Nigeria: An implication for HIV/AIDS preventive communication campaign. New Media and Mass Communication, 27.

Krieger, N. (2001). Theories for social epidemiology in the 21st century: An ecosocial perspective. International Journal of Epidemiology, 30(4), 668-677 https://doi.org/10.1093/ije/30.4.668.

Krieger, N. (2005). Embodiment: A conceptual glossary for epidemiology. Journal of Epidemiology \& Community Health, 59(5), $350-355$.

Krieger, N. (2012). Methods for the scientific study of discrimination and health: An ecosocial approach. American Journal of Public Health, 102(5), 936-944. https://doi.org/10.2105/AJPH.2011.300544.

Levins, R., \& Lopez, C. (1999). Toward an ecosocial view of health. International Journal of Health Services, 29(2), 261-293 https://doi.org/10.2190/WLVK-D0RR-KVBV-A1DH.

Marston, C., \& Cleland, J. (2003). Do unintended pregnancies carried to term lead to adverse outcomes for mother and child? An assessment in five developing countries. Population Studies, 57(1), 77-93.

McLaren, L., \& Hawe, P. (2005). Ecological perspectives in health research. Journal of Epidemiology and Community Health, 59(1), 6-14. https://doi.org/10.1136/jech.2003.018044.

McQuillan, K. (2004). When does religion influence fertility? Population and Development Review, 30(1), 25-56.

National Population Commission (NPC) [Nigeria] and ICF. (2019). Nigeria Demographic and Health Survey 2018. Abuja, Nigeria, and Rockville, Maryland, USA: NPC and ICF. 
Noor FR, Rahman MM, Rob U. and Bellows B. 2012 Unintended pregnancy among rural women in Bangladesh. Quarterly of Community Health Education 32(2): 101土113. doi: 10.2190/IQ.32.2.b PMID: 23000458

Oyediran, K. A. (2006). Fertility desires of Yoruba couples of South-western Nigeria. Journal of Biosocial Science, 38(5), 605-624.

Oyediran, K. A., \& Odusola, A. F. (2004). Poverty and the dynamics of women's participation in household decision-making in Nigeria. African Population, 19, 115-139.

Ram U. 2001. Unwanted pregnancies/births among tribal and Muslim of Maharashtra. Demography India,30(2):281-97.

Roy, T. K., \& Singh, B. P. (2016). Correlates of unwanted births in Bangladesh: A study through path analysis. PLoS One, 11(10), e0164007. https://doi.org/10.1371/journal.pone.0164007.

Sedgh, G., Bankole, A.r Oye-Adeniran, B., et al. (2006). Unwanted pregnancy and associated factors among Nigerian women. International Family Planning Perspectives, 32, 175-184.

Singer, M., \& Clair, S. (2003). Syndemics and public health: Reconceptualizing disease in bio-social context. Medical Anthropology Quarterly, 17(4), 423-441.

Singer, M. C., Erickson, P. I., Badiane, L., Diaz, R. V., Ortiz, D., Abraham, T. H., \& Nicolaysen, A. M. (2006). Syndemics, sex and the city: Understanding sexually transmitted diseases in social and cultural context. Social Science \& Medicine, 63(8), 20102021.

Stacey, Dawn. 2019. What do religions say about birth control and family planning, Very Well Health, https:/www. verywellhealth.com/what-are-religious-views-on-birth-control-906618

StataCorp. (2019). Stata Statistical Software: Release 16. College Station, TX: StataCorp LP.

Tebekaw, Y., Aemro, B., \& Teller, C. (2014). Prevalence and determinants of unintended childbirth in Ethiopia. BMC Pregnancy and Childbirth, 14, 326. https://doi.org/10.1186/1471-2393-14-326.

Westoff, Charles F., and Kristin Bietsch. 2015. Religion and reproductive behavior in sub-Saharan Africa. DHS Analytical Studies No. 48. Rockville, Maryland, USA: ICF International

Williams, L. B. (1991). Determinants of unintended childbearing among ever-married women in the United States: 1973-1988. Family Planning Perspectives, 23(5), 212-221. https://doi.org/10.2307/2135755.

World Bank 2018. Investing in Human Capita for Nigeria's Future. World Bank Group. http://documents.worldbank.org/ curated/en/346771542864299850/pdf/132316-21-11-2018-17-31-9-NigeriaBEUAMF.pdf

Yeatman, S., \& Sennott, C. (2015). The Sensitivity of Measures of Unwanted and Unintended Pregnancy Using Retrospective and Prospective Reporting: Evidence from Malawi. Maternal and Child Health Journal, 19(7), 1593-1600. https://doi.org/10. 1007/s10995-015-1669-2

\section{Publisher's Note}

Springer Nature remains neutral with regard to jurisdictional claims in published maps and institutional affiliations.

\section{Submit your manuscript to a SpringerOpen ${ }^{\circ}$ journal and benefit from:}

- Convenient online submission

- Rigorous peer review

Open access: articles freely available online

- High visibility within the field

- Retaining the copyright to your article

Submit your next manuscript at $\boldsymbol{\nabla}$ springeropen.com 